Guest Editorial, part of a Special Feature on Coupled Human-Coastal Ecosystems: Building Resilience through Teaching and Research Partnerships

\title{
Democratizing conservation science and practice
}

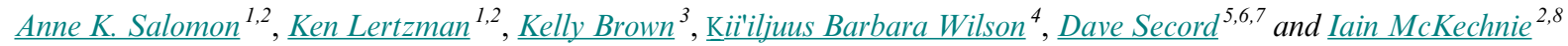

Key Words: Great Bear Rainforest; holocene; indigenous, knowledge coproduction; polycentric governance; resilience; social justice, environmental justice; traditional ecological knowledge

\section{INTRODUCTION}

Navigating the tightly linked problems of ecological sustainability and social justice is the central challenge facing humanity this century (Raworth 2012, Dearing et al. 2014). Although conservation science and practice have made great strides in steering society toward ecological sustainability, these endeavors have historically done so in the absence of recognizing social justice as a dual and equally important goal. This disconnect has often led to the failure of conservation and natural resource management initiatives that were inadequately grounded in their socio-cultural context, ignored or discounted alternative knowledge systems, or disregarded human rights and the equitable use of resources (Brondizio and Le Tourneau 2016, Hicks et al. 2016, Mistry and Berardi 2016). We provide some insights and perspectives on democratizing conservation science and practice yielded through a set of novel partnerships among scientists, natural resource managers, students, and Indigenous communities on Canada's west coast. These partnerships were catalyzed through an experiment in collaborative research and teaching that is showcased in this Special Feature.

What do we mean by the notion of democratization? Broadly put, democratization is the action of making something accessible to everyone. In the context of conservation science and practice, it is the process of ensuring that all knowledge holders have the right and opportunity to participate in scientific endeavors, voice their conservation objectives, and for their knowledge, values, and information sharing protocols to be equally considered. The democratization of conservation science implies a transition from what is often a top-down, authoritarian endeavor toward a more egalitarian one. Consequently, it demands that we broaden the definition of science to include multiple knowledge systems (e.g., traditional and local knowledge) and expand the practice of conservation science to include the participation and objectives of all those who wish to act collectively to support the stewardship of the biosphere. Although a variety of barriers to the democratization of conservation science and practice exists, an equally diverse set of actions can be used to overcome these barriers and catalyze new pathways toward achieving both ecologically sustainable and socially just outcomes. One such class of actions is our focus: the coproduction, collaborative dissemination, and application of knowledge.

Our objectives in this editorial are, first, to briefly introduce the social-ecological context of British Columbia (BC), Canada's
Central Coast, and the circumstances that catalyzed the papers in this Special Feature. Second, we use this experiment in collaborative research and teaching as a starting point to hypothesize specific mechanisms by which the simultaneous coproduction of knowledge and collaborative teaching can enhance the resilience of coupled social-ecological systems (SES). We then cast our net more broadly to share our perspectives on the key barriers and catalysts to democratizing conservation science and practice to navigate toward both ecologically sustainable and socially just outcomes. Through collaborative research, as reflected in the papers in this Special Feature, not only do diverse knowledge holders share power, but diverse sources of information, hypotheses, and skills increase the likelihood for transformative conservation science, expand the range of options for conservation actions, and can improve management decisions.

\section{THE CONTEXT: PEOPLE, PLACE, AND OUR EXPERIMENT}

The coastal temperate rainforests and marine ecosystems of British Columbia have been the subject of conflict over resource management and Indigenous rights since European colonization in the late 18 th century, intensifying over the past 150 years (Fisher 1977, Harris 2002, Lutz 2008). Indigenous people in coastal British Columbia, referred to as First Nations, have worked since contact to assert their rights, and most Nations have not ceded title to or rights concerning their lands and waters. In recent decades, renewed efforts and new relationships among First Nations, Provincial and Federal governments, and various conservation and resource interest groups have developed in the context of Supreme Court cases affirming various aspects of Indigenous title and rights. Moreover, some ancient Indigenous agreements and governance practices among First Nations have recently been reaffirmed, following shared traditional governance protocols, specifically the potlatch system, and the exchange of cultural property such as songs, dances, names, and stories affirming intercultural diplomatic relationships (e.g., Heiltsuk Haida Peace Treaty). We focus on the area from northern Vancouver Island to the Alaska border, including BC's Central Coast, North Coast, and Haida Gwaii that has come to be collectively known as the Great Bear Rainforest (Fig. 1). This land-sea continuum has been the subject of novel and landmark achievements in implementing ecosystem-based management, integrating ecological and human well-being outcomes, and

${ }^{1}$ School of Resource and Environmental Management, Simon Fraser University, ${ }^{2}$ Hakai Institute, ${ }^{3}$ Heiltsuk Integrated Resource Management Department, ${ }^{4}$ Department of Education, Simon Fraser University, ${ }^{5}$ Barnacle Strategies, ${ }^{6}$ Simon Fraser University, ${ }^{7}$ University of Washington, ${ }^{8}$ Department of Anthropology, University of Victoria 
developing nested, semiautonomous governance structures (Howlett et al. 2009, Price et al. 2009, McGee et al. 2010, Moore and Tjornbo 2012).

Fig. 1. Located along Canada's west coast is the Great Bear Rainforest, an area in British Columbia (BC) encompassing northern Vancouver Island, BC's Central Coast, North Coast, and Haida Gwaii. The Central Coast of $\mathrm{BC}$ has been home to four Indigenous communities, the Heiltsuk, Kitasoo/Xais'Xais, Nuxalk, and Wuikinuxv Nations, for at least 13,000 years.

Research showcased in this Special Feature was coproduced by scientists, students, and Indigenous collaborators in partnership with the Hakai Institute's (yellow circle) research and educational programs.

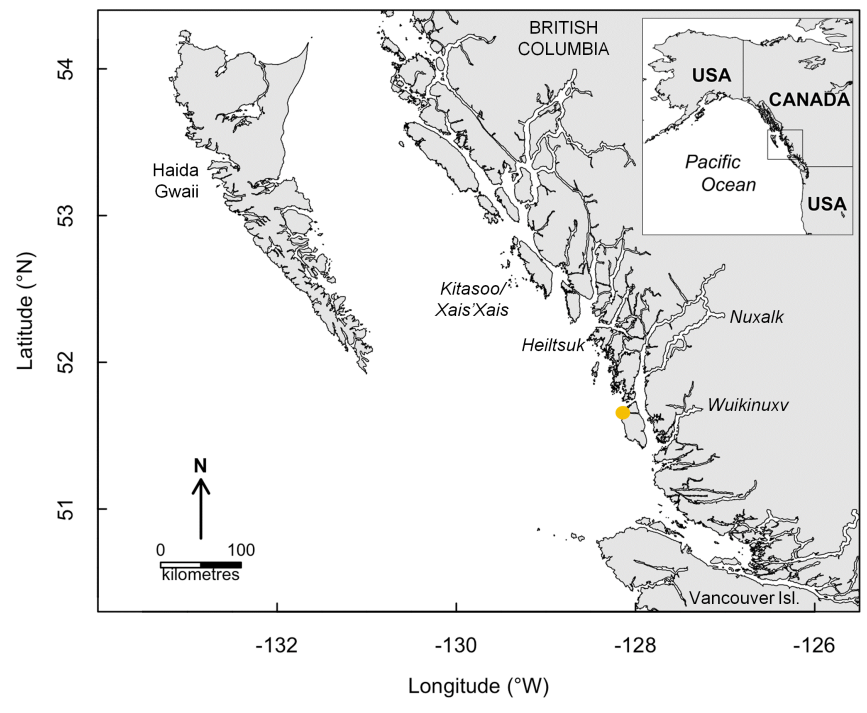

The Great Bear Rainforest is an area that is diverse culturally and ecologically, with archaeological evidence of continuous habitation by Indigenous peoples for at least 13,000 years (Mackie et al. 2011, McLaren et al. 2015). The region is the unceded territory of more than 25 First Nations, each holding distinct language dialects (Gessner et al. 2014), a proxy for cultural diversity. This large number of culturally distinct and politically autonomous groups holds territories that collectively span more than 7.5 million ha and continue to support a full complement of marine and terrestrial apex predators (i.e., brown and black bears, wolves, cougars, sea otters, orca whales), a proxy for ecological diversity and high productivity.

Archaeological and palaeoecological records show that people in this area have used diverse biological resources for millennia (Hebda and Mathewes 1984, McKechnie et al. 2014, Jackley et al. 2016), engaged in active management of those resources (Lepofsky and Lertzman 2008, White 2011, Jackley et al. 2016, Hoffman et al. 2017) and had highly developed systems of governance regulating access to and use of resources (Brown and Brown 2009, Trosper 2009, Gauvreau et al. 2017). Many of these governance systems continue to feature in harvest and stewardship practices today and many of these resources are central to modern diets, economies, and cultural activities. In the context of recent legal agreements and political commitments, First Nations of this region are reclaiming and exercising their rights to protect, conserve, utilize, and manage their traditional landscapes and seascapes (Adams et al. 2014, Housty et al. 2014, Lagasse et al. 2014, Jones et al. 2017, Ban and Frid 2018).

In 2009 , there was a novel intervention in this social-ecological system with the creation of a field research station in the heart of the Great Bear Rainforest. The Hakai Institute (https://www. hakai.org/) is a not-for-profit science facility that coordinates multidisciplinary, field-based research programs with a focus on long-term monitoring of coastal ecosystems. Research conducted by the Hakai Institute out of its Central Coast research station takes place in the traditional territories of the four Central Coast First Nations: the Heiltsuk, Wuikinuxv, Kitasoo/Xais'Xais, and Nuxalk (Fig. 1). This Special Feature is a compilation of six papers coproduced by researchers, including both western scientists and Indigenous knowledge holders, and developed in the context of the Hakai Institute and its associated research and educational programs.

This Special Feature was initiated with research projects arising from the Hakai-Simon Fraser University graduate field class in Resilience of Coastal Social-Ecological Systems, led by Salomon and Lertzman in 2012, 2013, and 2015 and grew to include contributions from a broader group of academic and Indigenous research partnerships involved with iterations of the course in some way. This course in itself was an experiment in collaborative teaching and coproduction of knowledge, intended to model resilience thinking in its design, participant experience, and in the outcomes of student-led research projects. It involved guest instructors from several coastal First Nations, scholars from many disciplines and institutions, and representatives of a variety of nongovernmental organizations. Our perspectives in this editorial are based on lessons learned via the resilience course, the scholarly literature in conservation science and resource management, ethnobiology, archaeology, political science, environmental law and social justice, and our collective experiences over many years with conservation and management as Indigenous and non-Indigenous researchers, policy advisors, and managers.

\section{BUILDING RESILIENCE THROUGH RESEARCH AND TEACHING PARTNERSHIPS}

Our aim in the resilience course was to simultaneously teach and advance resilience theory and practice by applying it to real-world management and decision-making challenges identified as priorities by Indigenous community partners. Using our course as an example, we use the principles of resilience described by Biggs et al. (2012) to develop hypotheses by which information generation (i.e., research) and flow among actors (i.e., teaching, mentoring, intergenerational, cross-cultural, and experiential knowledge exchange) could enhance the resilience of the Central Coast social-ecological system (Table 1). We link each principle to plausible mechanisms supporting them and to specific actions adopted in the course that reflected the mechanisms. For instance (Table 1), diverse sources of information can maintain SES diversity by increasing the likelihood of innovation and opportunities for adaptation, and redundancy in information can provide insurance against information loss or ineffectiveness (Biggs et al. 2012). Applying this to the course, we facilitated access to diverse sources of information, multiple learning modes and environments, and redundancy in the presentation of 
Table 1. Hypothesized mechanisms and empirical examples by which integrating collaborative information generation (i.e., research) and flow among actors (i.e., teaching and mentoring) can enable the coproduction of knowledge and build resilience of a socialecological system (SES) based on seven resilience principles described by Biggs et al. (2012). This structure could be used for designing and testing field courses and training programs as experiments in resilience thinking and practice.

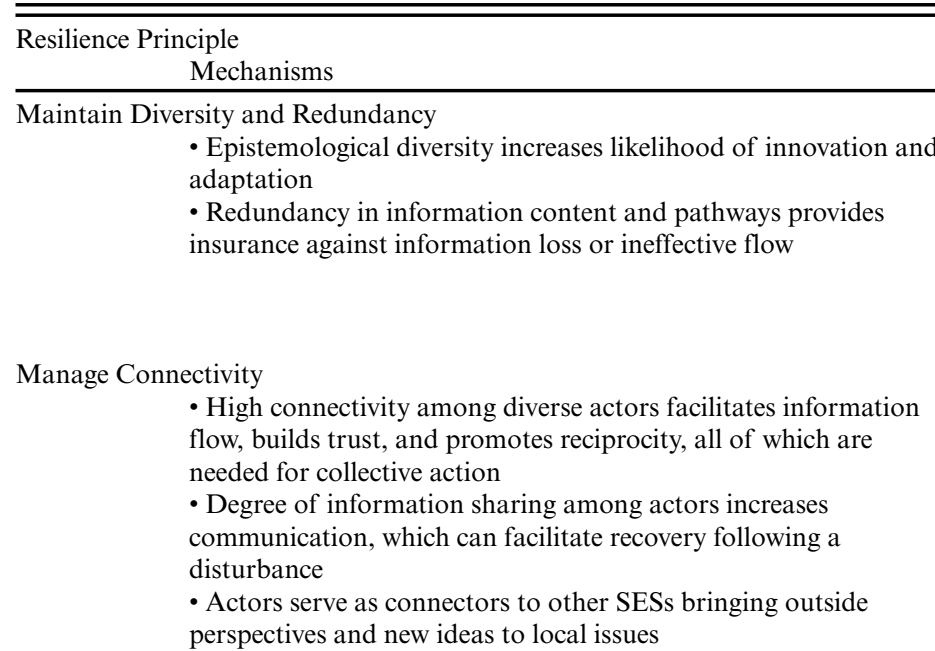

Manage Slow Variables and Feedbacks

- Information updates facilitate quick feedbacks within the system

- Ability of managers to respond to new perturbations is enhanced with new information

Foster Complex Adaptive Thinking

- Integrating collaborative research and teaching fosters a willingness to seek connections and feedbacks among system components, accept uncertainty, and adopt management approaches that incorporate these ideas

- Preparedness to cope with unexpected events supports adaptive thinking

-Willingness to embrace change increases with exposure to new and diverse information sources

Encourage Learning

- Innovation and willingness to experiment promotes learning

- Sharing of scientific resources and inferences

Broaden Participation

- Increased levels of participation, trust, and cooperation increase equitable sharing of knowledge

Promote Polycentric Governance

- Use of local Indigenous knowledge and stewardship protocols regionally can equalize the distribution of power in decision making and willingness to participate in conflict resolution
In-Class Applications

- Involvement of diverse instructors with unique worldviews, values, expertise, cultural backgrounds, and knowledge systems - Dialogue with a diversity of local governmental and nongovernmental organizations illuminated management problems and local to regional research priorities

- Diverse instructors reinforced related SES concepts within diverse SESs and learning contexts

- Initiating the class with community dialogues and intentional overlap with local management trainings facilitated diagnosis of local information needs, research codevelopment, and skills exchange

- Deliberate class overlap with larger research initiatives led to course research projects that advanced broader management and conservation goals

- Regional and international specialists provided both contrasting and reinforcing ideas

- Interaction with local stewardship managers facilitated responsiveness of class to local needs and of managers to new information generated by class research

- Direct relationships among class members, other researchers, and community members increased perceived legitimacy of research and allowed results to be put to use quickly

- The course was part of longer-term and ongoing collaborations among core participants

-We addressed ecosystem-based management principles, traditional stewardship principles, and community perspectives in class sessions and via applied research

- Class schedule and content was flexible and reorganized to benefit from unforeseen learning opportunities when they presented -We deliberately made time for unexpected teachable moments

- Participants and partners were aware of the experimental nature of the course

- We discussed problems and shared lessons with the participants when we made mistakes

- All class research results were presented back to local governing units and community members

- The creation of this open-access Special Feature exemplifies seizing an opportunity for teaching and learning that arose during the course

- We began and ended courses with community meetings - Community partners were involved in course design ahead of time and follow-up afterward

- Relevant work initiated outside the context of the class is included in this Special Feature

- Traditional knowledge was embedded within class research topics, methods, and inferences

- Efforts to decentralize power are reflected in the choice to work with local Indigenous governments, managers, and knowledge holders to codesign and coteach course and guide research projects 
information by involving knowledge holders from different perspectives, disciplines, and cultures. Speakers reinforced related SES themes (thresholds, scale, crises, traps, windows of opportunity, social innovation, and adaptive governance) with varying coastal SES examples (fisheries, forestry, protected areas, etc.) from their own perspectives. Furthermore, major themes were reinforced in diverse learning contexts: classroom sessions, field exercises, and community dialogues (Fig. 2).

Fig. 2. Facilitating resilience thinking and practice along British Columbia's Central Coast through novel research and teaching partnerships involved: (A) community dialogues, (B) field trips to local conservation education initiatives, (C) classroom sessions, (D) field training, (E) field research, and (F) sharing of knowledge by local experts such as Heiltsuk Archaeologist Gitla Elroy White. (Photos by A. K. Salomon)

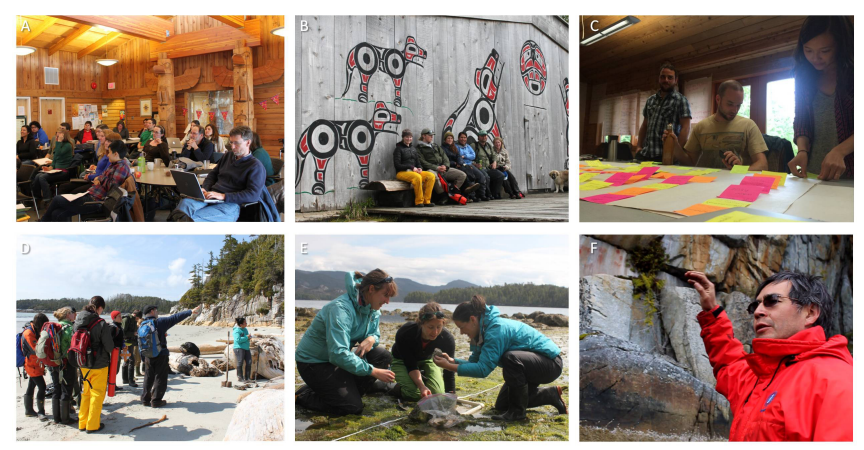

High levels of connectivity between social groups can confer resilience by increasing information sharing, the spread of new ideas, and the promotion of trust and reciprocity needed for collective action and recovery following a disturbance (Biggs et al. 2012). To enhance connectivity among actors in this SES, we intentionally scheduled the class to overlap with local management meetings and training sessions, such as the annual Coastal Stewardship Network gathering representing managers and stewardship staff, known as Guardian Watchmen, from First Nations across BC's coast. Each class also began with a community meeting and dinner. These facilitated interactions among class participants, Indigenous stewards, and the broader conservation and management community, allowing us to identify local issues, diagnose local information needs, codevelop research projects, and exchange skills (Klain et al. 2014, Lagasse et al. 2014, Jackley et al. 2016). By bringing in local experts and those with expertise in ecosystems, management systems, and social contexts elsewhere, we created a fertile arena to engage both reinforcing and contrasting ideas about SES dynamics.

One way to manage slow variables and feedbacks to support SES resilience (Biggs et al. 2012) is by maintaining the flow of information about variables that change at rates outside the normal perceptual frame of resource managers and assure that there are feedbacks between new information generated and those who can use it (Table 1). We did this by supporting the reciprocal flow of information among students, faculty, local managers, and community members, who held both distinct and overlapping time and spatial frames of observation and experience with the Central Coast SES. Establishing these direct relationships allowed new information to have legitimacy among community members (Pinkerton and John 2008), be directed quickly to those who could use it, and allowed the class to be responsive to local information needs.

Complex adaptive systems thinking (Biggs et al. 2012) can be fostered through collaborative research and teaching, which itself promotes a willingness to seek connections and feedbacks among disciplines and knowledge systems, to accept uncertainty, and to adopt applied research results that incorporate these ideas. This resilience principle is central to ecosystem-based management (EBM) as it has been expressed in the Great Bear Rainforest agreement (Price et al. 2009). The resilience class incorporated detailed discussions of how this principle is reflected, or not, in local conservation and management initiatives and the challenges of implementation. Several coastal First Nations in British Columbia have core traditional stewardship principles guiding their relationships with the environment that resonate strongly with the notions of complexity, connectedness, and feedbacks in adaptive systems. For instance, the Nuu-chah-nulth Nations along the west coast of Vancouver Island use Hishuk Ish Tsawalk, to express the principle "Everything is One" or "Everything is Connected" (Umeek 2004). Similarly, the Haida concept of Gina 'waadluxan gud ad kwaagid, means "Everything depends on everything" (Kii'iljuus Wilson and Luu Gaahlandaay Borserio 2011).

The Resilience class reflected the resilience principles of encouraging learning and broadening participation (Table 1) comprehensively in its design. Local stewardship managers were involved in the early design phase of the class each year so that new ideas, pressing topics, and lessons learned from previous years could be incorporated into the upcoming class objectives, content, and learning outcomes. Examples include the students' awareness of the experimental nature of the class, collective discussion of our mistakes and the lessons learned from them, inclusiveness in course participation, and reporting back to the local managers and communities on the research products. Producing this Special Feature, and its expansion beyond the original class participants, reflects our intent to share the knowledge and lessons of the course with a broader audience.

Finally, polycentric governance can facilitate the exchange and use of traditional and local knowledge and thereby enhance the resilience of social-ecological systems (Biggs et al. 2012). In the Great Bear Rainforest, there have been recent, profound shifts in natural resource governance that reflect a return of some jurisdictional authority to local Indigenous governments (e.g., Haida Gwaii Reconcilation Act, Haida Gwaii Land Use Objectives Order, Great Bear Initiative, Great Bear Rainforest Land Use Order, Marine Plan Partnership, Northern Shelf Bioregion Marine Protected Area Network Planning). Our choices to run the resilience course on the Central Coast, to work with local nations in designing and carrying it out, in the selection of research projects, and in the details of course design were all made in the context of supporting the shift toward adaptive, polycentric governance and the ability of local First Nations people and institutions to assert their autonomy, knowledge, management authority, and capacity to use, manage, and conserve ecosystems effectively.

Collectively, the papers emerging from the resilience class offer strong support for the idea that a course such as this can advance 
scientific understanding (i.e., discover SES phenomena, generate novel hypotheses) by challenging traditional conservation science monism and by instead recognizing the value of pluralism in our field (Matulis and Moyer 2017). In the teaching and research generated by this class, parallel sources of wisdom, concerning the same place and the same questions, were given the chance to challenge, inform, and improve one another. The papers in this Special Feature and their associated research and outreach programs also reinforce how epistemological and cultural diversity enrich learning experiences with outcomes that provide personal, intellectual, relational, and conservation legacies that return value well after the course and its broader associated research programs are over. The coproduction and collaborative dissemination of knowledge that was enabled by way of this graduate class provides a concrete example of how it is possible to overcome key barriers to the democratization of conservation science and practice.

\section{BARRIERS AND CATALYSTS TO DEMOCRATIZING CONSERVATION SCIENCE AND PRACTICE}

To explore the broader lessons that emerge about conditions that inhibit or enable a transition toward a more pluralistic approach to conservation science and practice, we identified six pairs of contrasting barriers and catalysts to the democratization process (Table 2).

\section{Scientific imperialism vs. coproduction of knowledge}

Whether conscious or subconscious, the common assumption that Western science is the primary tool to initiate questions, generate hypotheses, collect data, and produce knowledge is prevalent among academic and government institutions, the scholars that inhabit them, and the funding agencies that support them. Because knowledge is routinely used to claim truth (Díaz et al. 2015), those who produce knowledge often define "truth" and thereby hold power. However, fundamental inequalities exist in how knowledge systems are valued and in their prominence in decision making. Scientific knowledge is often viewed as objective, precise, and empirical, lending credibility and legitimacy. In contrast, traditional and local knowledge are often viewed as subjective, biased, and qualitatively imprecise (Mistry and Berardi 2016).

Whether intended or not, Western scientific imperialism marginalizes other knowledge sources and systems, creating strong power imbalances between those who are deemed able to define truth and those who are not. At best, this form of intellectual elitism can stifle scientific innovation and cause wellintentioned conservation efforts to have suboptimal, unexpected, or even perverse results. At its worst, the lack of shared power with traditional knowledge holders to use their knowledge to inform conservation and management decisions can trigger crisis, revolt, and litigation. Recent local examples include the 2015 conflict between the Heiltsuk Nation and Canada's Federal Fisheries Agency over the conservation of Pacific herring and multiple preceding court injunctions by several coastal Indigenous communities over similar issues (von der Porten et al. 2016, Jones et al. 2017). Fortunately, there is a plethora of ways to remedy this pathology (Table 2) and the number of successful ecosystem science and conservation initiatives informed by multiple knowledge systems is growing (Mistry and Berardi 2016).
Sharing power in the scientific process starts by seeking research partnerships with Indigenous communities using free, prior, and informed consent (Menzies 2004, UN 2007, TRC 2015). This explicitly means being prepared for a research proposal or request to be declined if that is the community's choice. It also means abiding by the distinct and often formal protocols that each community has for engagement. Although following protocol may seem like a barrier to many researchers, quite often the opposite is true. Adhering to the locally defined set of rules and practices for engagement opens doors and enables equitable partnerships. For example, protocols identify who, or what group, in the community has the authority to provide consent.

If consent is given, sourcing research ideas from communities and codeveloping research questions of genuine mutual interest at the initiation of a project simultaneously shares power and increases the relevance of the research itself. Not only is relevance improved, but the breadth of ideas and interpretations obtained can be substantially greater than would arise from a narrower set of actors and worldviews (Adams et al. 2014, Poe et al. 2014). The assembly and active use of a diverse research advisory board can provide the same benefits if it is one that includes Indigenous knowledge holders, resource users, scientists, and managers that equitably share the authority to advise the research program. Doing so builds trust, enables the capacity for vital course corrections, and increases the likelihood of research results being applied to key conservation and management decisions. Lastly, treating local and traditional knowledge as one of many data sources that, like all data, carries uncertainty, helps foster a dialectic between knowledge systems. Truth can then be jointly sought through the exchange of information, multiple lines of evidence (Tengö et al. 2014), and inferences and reasoning by diverse knowledge holders while respectfully acknowledging distinct epistemologies. These dialectics are further enabled by translating specialized scientific terminology into nontechnical language and exchanging scientific skills to support local scientific capacity and autonomy.

\section{Scientific reductionism vs. thinking in systems}

The ecological and social dimensions of environmental problems are often studied in isolation, despite being subcomponents of the same complex adaptive system (Ban et al. 2013). Although reducing complex systems into their component pieces is a common way of coping with complexity, it precludes system-wide analysis and thus an understanding of the critical feedbacks that generated the problem in the first place (Meadows 2009). Scientific reductionism is also reflected in the disciplinary way universities tend to train environmental science students, tomorrow's managers, policy makers, and conservation leaders. However, as the magnitude of human impacts on the Earth's biosphere continues to accelerate, there is a growing recognition of the intimate coupling and coevolution between ecosystems and human systems (Folke et al. 2016). Achieving an integrated understanding of the coupled dynamics of SESs remains a central challenge for both researchers and managers (Lertzman 2009).

Mounting evidence suggests that conservation and management interventions linking ecological and social processes lead to outcomes that outperform those that do not (Gutiérrez et al. 2011, Schultz et al. 2015, Cinner et al. 2016, Gill et al. 2017). This is because explicitly recognizing the feedbacks between ecological 
Table 2. Barriers and catalysts to the democratization of conservation science and practice.

\begin{tabular}{l}
\hline Barriers \\
\hline Scientific Imperialism \\
- The assumption that Western science is the \\
primary tool to initiate questions, generate \\
hypotheses, collect data, produce knowledge, \\
and thereby arbitrate truth \\
- The use of technical language that obscures \\
information flow and impedes learning by \\
nonspecialists
\end{tabular}

Scientific Reductionism

- Tendency to reduce research problems into component parts

- Disciplinary teaching and training

Anthropocene Myopia

- Ignorance, or intentional disregard of past conservation technologies and lessons

The Loading-Dock Problem

- The assumption that all science, as soon as it is produced, is relevant, has immediate use, and can be understood and used

- In which science produces knowledge that is communicated in ways that cannot be effectively used in policy

Neoliberal Worldview

- The assumption that economic efficiency, private property rights, and the devolution of responsibilities and risks to the private sector will optimize natural resource use

Centralized Resource Governance

- In which deliberation, decision making, power, and legal authority are vested within a central body
Catalysts

Coproduction of Knowledge

- Share power through collaboratively designed research

- Seek research partnerships using free, prior, and informed consent

- Source research ideas from communities and codevelop research questions of mutual interest at project initiation

- Construct and use diverse and equitable science advisory boards

- Consider traditional knowledge, including oral histories, as a source of information which,

like all data, carries uncertainty

- Foster a dialectic between knowledge systems

- Strengthen local scientific capacity and autonomy by exchanging skills

- Translate scientific terminology into nontechnical language

Thinking in Systems

- Recognize that humans and ecosystems are inextricably linked

- Explicitly identify short-term feedbacks and long-term coevolution between ecosystems

and human systems

- Firmly link ecological and social system processes in research question generation, data

collection, and inference

- Teach and train the next generation of transdisciplinary researchers, managers, social innovators, and policy makers

Holocene Hyperopia

- Recognize evidence of conservation practices and principles that predate colonial, neoliberal economies

- Consider technologies and principles that evolved in the Holocene may be retooled to inform conservation challenges today

- Study lessons from past successes and failures from diverse cultures and social-ecological contexts

Policy-Ready Science

- Involve resource users, managers, policy makers, legal scholars, and lawyers in problem definition, research method design, and in the application of results to assess alternative policy options

- Seek to understand the problem from the viewpoint of all impacted actors and system components

- Communicate to a broad audience by using multiple modes of communication

Alternative Nonmarket Worldviews

- Consider alternative noninstrumental worldviews to management and conservation and the different values and objectives they engender

- Recognize and respect noninstrumental values of the biosphere to cultural integrity and human well-being

Polycentric Governance

- Link independent decision-making units within a specified geographic area to other units

horizontally and nest them within broader governance units vertically

- Inform decisions with local, scale-specific knowledge, and objectives

- Share power and authority across these governing scales

- Share decision-making authority through comanagement arrangements

${ }^{\dagger}$ In Canada, this entails being consistent with the Canadian Constitution, which means respecting Indigenous Canadian governments as sovereign nations and recognizing aboriginal rights.

and social systems can prevent perverse or unexpected results of well-intentioned conservation efforts (Turner et al. 2013, Wolverton et al. 2014, Nabhan 2016). Although management is the sum of actions taken to guide a system toward achieving desired goals and objectives, a management system is the sum of these actions, goals and objectives, and the process through which they are legitimized by social norms and the institutions and actors involved in carrying them out (Lertzman 2009). Reframing the concept of management to the broader, more inclusive idea of management system will enable better understanding of how social and ecological dynamics act as coupled drivers of managed ecosystems (Table 2). Given this reframing, vast opportunity lies in improving our understanding of the social psychology driving social norms and legitimacy in management systems today.

\section{Anthropocene mypopia vs. Holocene hyperopia}

Given science and society's infatuation with contemporary technological solutions to contemporary problems, we tend to ignore the past. For example, despite long-term coevolutionary 
feedbacks between social systems and ecosystems (Armstrong et al. 2017), innovations in conservation principles and practices generated from millennia of resource use, overuse, learning, and adaptation (Anderson 1996, Berkes 1999, Turner and Berkes 2006) have yet to be fully tapped by conservation scientists and practitioners (Rick et al. 2008, Rick and Erlandson 2009, Braje et al. 2017). And yet in many cases, technical innovations from the Holocene could be retooled to help solve environmental challenges in the Anthropocene (Table 2). For example, ancient clam gardens, intertidal rock walled terraces constructed by Indigenous peoples in the Holocene, can double clam production (Groesbeck et al. 2014). This ancient form of shellfish mariculture and associated access rights (Lepofsky et al. 2015) could be used to enhance local food security and sovereignty today. Moreover, the portfolio of ancient coastal conservation and management practices in which clam gardens were embedded (Jackley et al. 2016) could have synergistic conservation value across coastal seascapes nowadays.

A diversity of Indigenous conservation principles, practices, and laws that evolved throughout the Holocene (Borrows 2002) could support adaptation to complex and urgent crises in the Anthropocene. Archaeological and ethnographic evidence suggests that complex governance systems and protocols, which predate colonial ones, conferred resilience and sustainability among Northwest Coast Indigenous communities for millennia (Trosper 2009, Campbell and Butler 2010, Lepofsky et al. 2015). For example, reciprocity and contingent proprietorship have long been key principles in traditional resource management among Northwest Coast Indigenous peoples (Trosper 2009, Powell 2012, Gauvreau et al. 2017). These same principles are now re-emerging from contemporary analyses as key to successful resource management (Gutiérrez et al. 2011). These include spatially explicit, designated access privileges for fisheries, such as marine tenures and very clear laws about the equitable distribution of resources among participants (Housty et al. 2014, Jackley et al. 2016, Gauvreau et al. 2017).

Consequently and not surprisingly, in North America's Indigenous context, the democratization of conservation science also implies supporting Indigenous language revitalization and art. Indigenous words, stories, and art, all expressions of the evolution of knowledge, and in many cases proprietorship and stewardship, can reveal traditional conservation principles, practices, and laws that can inform and improve today's management context. The practice of building clam gardens, although only recently recognized by Western science, is captured by various coastal First Nations words, such as lúx xiwey and wúxwuthin (Deur et al. 2015, Lepofsky et al. 2015). Ancient management technologies and practices are often tied to traditional terminology through words or expressions, which reinforce the antiquity of these practices. Revitalizing and researching Indigenous language could lead to other equally "new" and exciting rediscoveries of past conservation and management innovations (e.g., Turner 2008, Turner 2014). For example, the Heiltsuk and Haida Nations have very specific words for traditional laws regulating the interaction between humans and the natural world (Housty et al. 2014, Gauvreau et al. 2017) many of which could help reshape conservation approaches and policies today. Moreover, Indigenous place names can indicate past resource distribution, abundance, and use (McKechnie et al.
2014). These spatially explicit data can illuminate magnitudes of change in species' population trends and spatial ranges today. And yet, globally, language diversity is being lost at a faster rate than Earth's biological diversity and with that loss of language comes the loss of previous conservation technologies and stewardship practices (Maffi 2005, Davis 2009). The revitalization of Indigenous languages could support the revitalization of some of those coevolved advancements in conservation strategies.

\section{The loading-dock problem vs. policy-ready science}

Unfortunately, conservation science commonly goes unused. Cash et al. (2006) refered to this as the loading-dock problem, in which scientists publish their results in documents that are then left on a loading dock, waiting to be picked up and used by practitioners (Cash et al. 2006). An antidote to this problem is increased engagement between researchers and decision makers and with communities who will use that science.

The loading-dock problem can be overcome by researchers that involve some combination of resource users, managers, policy makers, and legal scholars in problem definition, research method design, and the application of results to test alternative policy options (Table 2). The Ocean Tipping Points project is a valuable example of this (http://oceantippingpoints.org). Moreover, researchers that seek to understand the problem from the viewpoint of people and system components can act as honest brokers of evidence for alternative policy options (Pielke 2007).

Sharing scientific research results with all actors within an SES, a key aspect to the democratization of conservation science, demands an appreciation for the diverse modes of communication used among actors (Table 2), many of which fall outside the conventional tools of science communication. Local cultural advisors, within the types of advisory boards described, can offer guidance on new and relevant dissemination approaches, exemplified by a collaborative research and communication initiative in the region of our focus: Coastal Voices (http:// coastalvoices.net).

\section{Neoliberalism vs. alternative nonmarket worldviews}

Many natural scientists presume that Western science-based management is value neutral, but all of our management systems are conditioned by our worldviews and our beliefs about the right and wrong way to interact with the environment (Lertzman 2009). Across North America and Western Europe, neoliberalism has been a dominant worldview shaping natural resource management objectives since the 19th century (Pinkerton and Davis 2015) and has been reified in its dominance in recent decades. A neoliberal worldview assumes that the best way to ensure widespread societal prosperity is to optimize the efforts of self-interested entrepreneurs efficiently by way of self-regulating markets (Hartwick and Peet 2003). In practical terms, it assumes that economic efficiency, private property rights, and the devolution of responsibilities and risks to the private sector will optimize natural resource management (Pinkerton and Davis 2015). Across the world, contemporary conservation ideologies and initiatives are heavily influenced by Western agendas (Mistry and Berardi 2016), which, in many cases, are shaped by neoliberal worldviews. Examples include the various payments for ecosystem services projects that exist worldwide. Neoliberal worldviews tend to produce management and conservation systems that focus on utilitarian values, and the commodification 
of ecosystems and conservation science has lent its skills to this commodification. This perspective stands in contrast to the nonmarket worldviews held by many Indigenous communities and the place-based relational values and management objectives they engender.

The purpose of natural resource management is to manifest in practice the normative values of society that are reflected in policies, plans, and accepted behaviors. Managers generally manage to achieve goals or targets that are set outside the management system by societal norms and values (Lertzman 2009). However, conflicts about management frequently arise because various distinct communities in society differ in their values in relation to natural resources and thus the management practices and approaches they desire (Lertzman 2009). Unfortunately, Indigenous values and conservation objectives are often not accounted for in contemporary natural resource management (Plagányi et al. 2013). Furthermore, there is still a tendency among the scientific community to assimilate traditional ecological knowledge within the Western worldviews of managing nature (Mistry and Berardi 2016). For example, Indigenous knowledge and community monitoring are institutionalized as part of the United Nations' REDD+ climate change mitigation program, a market-based approach to carbon abatement.

A step toward overcoming these challenges is to recognize alternative worldviews to environmental management and conservation and the different values and management objectives they can engender (Table 2). The relationships of Indigenous peoples to the ecosystems in which they live are not only reflected in an intimate knowledge of those systems, but a structure of beliefs about their role in the world, their values, practices, social institutions, and relationships (Anderson 1996, Berkes 1999, Turner and Berkes 2006, Kimmerer 2013). The term resource itself describes a stock or a supply, be it material, services, or some other asset, from which benefit is produced. It does not imply any notion of reciprocity or respect, core concepts in many Indigenous worldviews (Brown and Brown 2009, Trosper 2009). In fact, the notion of reducing ecosystem processes only to instrumental values has also been challenged by many non-Indigenous writers both within and outside the conservation science community (Chan et al. 2016). Recognizing, respecting, and accounting for noninstrumental values of our biosphere to its diverse occupants' health and well-being can enable more equitable management and conservation decisions.

\section{Centralized vs. polycentric governance}

Centralized resource governance is the norm among North American and European nations, often creating problems of fit in which the scale of management fails to match the scales of the ecological and social processes they are intending to manage (Folke et al. 2007). In the context of Indigenous communities in Canada, centralized governance reflects a legacy of colonialism and remains a key barrier to local Indigenous authority in decision making and self-determination (Turner et al. 2013, Coburn and Atleo 2016). Polycentric institutional arrangements, that is, nested, quasi-autonomous decision-making units operating at multiple scales, offer a means by which to address the problem of fit (Ostrom 2005).
By capitalizing on scale-specific knowledge and diverse knowledge systems, polycentric governance can facilitate the sharing of information and capacity among system actors. We view this as both a broad catalyst of the democratization of conservation science (Table 2) and a resilience principle that we enacted in this multiyear graduate class (Table 1). Nested scales of governance also provide a balance between decentralized and centralized decision making, thereby facilitating the joint management of common pool resources (Ostrom 2005). Around the world, the devolution of power and authority to manage the environment has created both the need and fertile testing grounds for polycentric governance structures that can cope with multiuser groups and decision making across scales (Cudney-Bueno and Basurto 2009).

\section{CONCLUSIONS: VISIONING THE FUTURE}

Although the history of conservation and resource management is rife with challenges in both the ecological and social dimensions (Ludwig et al. 1993, Holling and Meffe 1996, Acheson 2006), there are exciting initiatives advancing the frontiers of social-ecological resilience and sustainability science (Armitage et al. 2009, Brondizio and Tourneau 2016, Folke et al. 2016, Levin and Poe 2017, Tengö et al. 2017). The process of democratizing conservation science and practice via meaningful collaborations between researchers and Indigenous communities is a significant aspect of what is exciting. Conservation science is well positioned compared to other sciences (e.g., physics) in this regard because of its place-based, transdisciplinary nature, and the embeddedness of conservation science in its social context. Conservation science practitioners are thus ideally placed to take a leadership role in advancing the dual problem of managing human activities within planetary boundaries and addressing issues of social justice and equity (Raworth 2012, Dearing et al. 2014). Problems of governance, especially decentralization and polycentricity in relation to Indigenous communities, are key to this (Brondizio and Tourneau 2016). Furthermore, local ecological knowledge, the touchstone of successful conservation practice, and a strength of Indigenous community partners, is at the core of successful environmental governance, resilience, and adaptation (Mistry and Berardi 2016).

However, institutional inertia among scientific, educational, and governing bodies remains a significant barrier to the transformation of conservation science and practice. Exploiting windows of opportunity to catalyze change and provide role models via research and teaching is a clear, if only partial, solution. This polycentric, geographically distributed strategy can be adopted broadly across the research community. There is a pressing need to train the next generation of researchers, managers, policy makers, social innovators, and leaders in: (1) the methods of coproducing knowledge and benefits of using multiple lines of evidence and knowledge systems (Salomon et al. 2007, 2011, Tengö et al. 2014); (2) social-ecological systems thinking; and (3) innovations from the Holocene that can inform the Anthropocene. This was the motivation for our class and for the Special Feature.

Responses to this article can be read online at: http://www.ecologyandsociety.org/issues/responses. $\mathrm{php} / 9980$ 


\section{Acknowledgments:}

We thank the many knowledge holders that took part in this collaborative research and teaching initiative; William Atlas, Susan Anderson-Bean, Jonaki Bhattacharyya, Frank Brown, Kathy Brown, Jennifer Carpenter, Daryl Fedje, William Gladstone, Keith Gladstone, Lance Gunderson, Duncan McLaren, Margot HessingLewis, Buzz Holling, Gary Housty, William Housty, Harvey Humchitt, Quentin Mackie, Reg Moody, Allyson Quinlan, Mike Reid, Ron Trosper, Nancy Turner, Andrea Vickers, Josh Vickers, Jennifer Walkus, Marty Weinstein, Gitla Elroy White, Laurie Whitehead, Evelyn Windsor, and our diverse and dedicated students. We thank Maria Tengo for providing valuable references, Alejandro Frid for his thoughtful contributions, Hannah Kobluk for preparing the map, and Dana Lepofsky for her insights and thorough review of an earlier version of this manuscript. We are indebted to Eric Peterson and Christina Munck for enabling this and other research and teaching initiatives on BC's coast. The Resilience graduate class was conducted in collaboration with the Heiltsuk Integrated Resource Management Department, Wuikinuxv Stewardship Office, Central Coast Indigenous Resource Alliance, and the Hakai Institute. Funding supporting this course, and the Hakai Network for Coastal Peoples, Ecosystems and Management, in which it was embedded, was provided by the Tula Foundation and collaborative teaching grants from Simon Fraser University to AKS.

\section{LITERATURE CITED}

Acheson, J. M. 2006. Institutional failure in resource management. Annual Review of Anthropology 35:117-134. http:// dx.doi.org/10.1146/annurev.anthro.35.081705.123238

Adams, M. S., J. Carpenter, J. A. Housty, D. Neasloss, P. C. Paquet, C. Service, J. Walkus, and C. T. Darimont. 2014. Toward increased engagement between academic and Indigenous community partners in ecological research. Ecology and Society 19(3):5. http://dx.doi.org/10.5751/ES-06569-190305

Anderson, E. N. 1996. Ecologies of the heart: emotion, belief, and the environment. Oxford University Press, Oxford, UK.

Armitage, D. R., R. Plummer, F. Berkes, R. I. Arthur, A. T. Charles, I. J. Davidson-Hunt, A. P. Diduck, N. C. Doubleday, D. S. Johnson, M. Marschke, P. McConney, E. W. Pinkerton, and E. K. Wollenberg. 2009. Adaptive co-management for socialecological complexity. Frontiers in Ecology and the Environment 7(2):95-102. http://dx.doi.org/10.1890/070089

Armstrong, C. G., A. C. Shoemaker, I. McKechnie, A. Ekblom, P. Szabó, P. J. Lane, A. C. McAlvay, O. J. Boles, S. Walshaw, N. Petek, K. S. Gibbons, E. Quintana Morales, E. N. Anderson, A. Ibragimow, G. Podruczny, J. C. Vamosi, T. Marks-Block, J. K. LeCompte, S. Awâsis, C. Nabess, P. Sinclair, and C. L. Crumley. 2017. Anthropological contributions to historical ecology: 50 questions, infinite prospects. PloS one 12(2):e0171883. http://dx. doi.org/10.1371/journal.pone.0171883

Ban, N. C., and A. Frid. 2018. Indigenous peoples' rights and marine protected areas. Marine Policy 87:180-185. http://dx.doi. org/10.1016/j.marpol.2017.10.020

Ban, N. C., M. Mills, J. Tam, C. C. Hicks, S. Klain, N. Stoeckl, M. C. Bottrill, J. Levine, R. L. Pressey, T. Satterfield, and K. M.
A. Chan. 2013. A social-ecological approach to conservation planning: embedding social considerations. Frontiers in Ecology and the Environment 11(4):194-202. http://dx.doi.org/10.1890/110205

Berkes, F. 1999. Sacred ecology: traditional ecological knowledge and resource management. Taylor and Francis, Philadelphia, Pensylvania, USA.

Biggs, R., M. Schlüter, D. Biggs, E. L. Bohensky, S. BurnSilver, G. Cundill, V. Dakos, T. M. Daw, L. S. Evans, K. Kotschy, A. M. Leitch, C. Meek, A. Quinlan, C. Raudsepp-Hearne, M. D. Robards, M. L. Schoon, L. Schultz, and P. C. West. 2012. Toward principles for enhancing the resilience of ecosystem services. Annual Review of Environment and Resources 37:421-448. http:// dx.doi.org/10.1146/annurev-environ-051211-123836

Borrows, J. 2002. Recovering Canada: the resurgence of Indigenous law. University of Toronto Press, Toronto, Ontario, Canada.

Braje, T. J., T. C. Rick, P. Szpak, S. D. Newsome, J. M. McCain, E. A. E. Smith, M. Glassow, and S. L. Hamilton. 2017. Historical ecology and the conservation of large, hermaphroditic fishes in Pacific Coast kelp forest ecosystems. Science Advances 3(2): e1601759. http://dx.doi.org/10.1126/sciadv.1601759

Brondizio, E. S., and F.-M. Le Tourneau. 2016. Environmental governance for all. Science 352(6291):1272-1273. http://dx.doi. org/10.1126/science.aaf5122

Brown, F., and Y. K. Brown. 2009. Staying the course, staying alive: coastal First Nations fundamental truths: biodiversity, stewardship and sustainability. Biodiversity BC, Victoria, British Columbia, Canada. [online] URL: http://www.biodiversitybc. org/assets/Default/BBC Staying the Course Web.pdf

Campbell, S. K., and V. L. Butler. 2010. Archaeological evidence for resilience of Pacific Northwest salmon populations and the socioecological system over the last $\sim 7,500$ years. Ecology and Society 15(1):17. http://dx.doi.org/10.5751/ES-03151-150117

Cash, D. W., J. C. Borck, and A. G. Patt. 2006. Countering the loading-dock approach to linking science and decision making. Science, Technology, and Human Values 31(4):465-494. http://dx. doi.org/10.1177/0162243906287547

Chan, K. M. A., P. Balvanera, K. Benessaiah, M. Chapman, S. Díaz, E. Gómez-Baggethun, R. Gould, N. Hannahs, K. Jax, S. Klain, G. W. Luck, B. Martín-López, B. Muraca, B. Norton, K. Ott, U. Pascual, T. Satterfield, M. Tadaki, J. Taggart, and N. Turner. 2016. Opinion: why protect nature? Rethinking values and the environment. Proceedings of the National Academy of Sciences 113(6):1462-1465. http://dx.doi.org/10.1073/pnas.1525002113

Cinner, J. E., C. Huchery, M. A. MacNeil, N. A. Graham, T. R. McClanahan, J. Maina, E. Maire, J. N. Kittinger, C. C. Hicks, C. Mora, E. H. Allison, S. D'Agata, A. Hoey, D. A. Feary, L. Crowder, I. D. Williams, M. Kulbicki, L. Vigliola, L. Wantiez, G. Edgar, R. D. Stuart-Smith, S. A. Sandin, A. L. Green, M. J. Hardt, M. Beger, A. Friedlander, S. J. Campbell, K. E. Holmes, S. K. Wilson, E. Brokovich, A. J. Brooks, J. J. Cruz-Motta, D. J. Booth, P. Chabanet, C. Gough, M. Tupper, S. C. A. Ferse, U. R. Sumaila, and D. Mouillot. 2016. Bright spots among the world's coral reefs. Nature 535(7612):416-419. http://dx.doi.org/10.1038/nature18607

Coburn, E., and C. Atleo. 2016. Not just another social movement: Indigenous resistance and resurgence. Pages 176-194 
in W. K. Carroll and K. Sarker, editors. In a world to win: contemporary social movements and counter-hegemony. ARP, Winnipeg, Manitoba, Canada.

Cudney-Bueno, R., and X. Basurto. 2009. Lack of cross-scale linkages reduces robustness of community-based fisheries management. Plos One 4(7). http://dx.doi.org/10.1371/journal. pone. 0006253

Davis, W. 2009. The Wayfinders: why ancient wisdom matters in the modern world. House of Anansi, Toronto, Ontario, Canada.

Dearing, J. A., R. Wang, K. Zhang, J. G. Dyke, H. Haberl, M. S. Hossain, P. G. Langdon, T. M. Lenton, K. Raworth, S. Brown, J. Carstensen, M. J. Cole, S. E. Cornell, T. P. Dawson, C. P. Doncaster, F. Eigenbrod, M. Flörke, E. Jeffers, A. W. Mackay, B. Nykvist, and G. M. Poppy. 2014. Safe and just operating spaces for regional social-ecological systems. Global Environmental Change-Human and Policy Dimensions 28:227-238. http://dx.doi. org/10.1016/j.gloenvcha.2014.06.012

Deur, D., A. Dick, K. Recalma-Clutesi, and N. J. Turner. 2015. Kwakwaka'wakw "clam gardens." Human Ecology 43(2):201-212. http://dx.doi.org/10.1007/s10745-015-9743-3

Díaz, S., S. Demissew, J. Carabias, C. Joly, M. Lonsdale, N. Ash, A. Larigauderie, J. R. Adhikari, S. Arico, A. Báldi, A. Bartuska, I. A. Baste, A. Bilgin, E. Brondizio, K. M. A. Chan, V. E. Figueroa, A. Duraiappah, M. Fischer, R. Hill, T. Koetz, P. Leadley, P. Lyver, G. M. Mace, B. Martin-Lopez, M. Okumura, D. Pacheco, U. Pascual, E. S. Pérez, B. Reyers, E. Roth, O. Saito, R. J. Scholes, N. Sharma, H. Tallis, R. Thaman, R. Watson, T. Yahara, Z. A. Hamid, C. Akosim, Y. Al-Hafedh, R. Allahverdiyev, E. Amankwah, S. T. Asah, Z. Asfaw, G. Bartus, L. A. Brooks, J. Caillaux, G. Dalle, D. Darnaedi, A. Driver, G. Erpul, P. EscobarEyzaguirre, P. Failler, A. M. M. Fouda, B. Fu, H. Gundimeda, S. Hashimoto, F. Homer, S. Lavorel, G. Lichtenstein, W. A. Mala, W. Mandivenyi, P. Matczak, C. Mbizvo, M. Mehrdadi, J. P. Metzger, J. B. Mikissa, H. Moller, H. A. Mooney, P. Mumby, H. Nagendra, C. Nesshover, A. A. Oteng-Yeboah, G. Pataki, M. Roué, J. Rubis, M. Schultz, P. Smith, R. Sumaila, K. Takeuchi, S. Thomas, M. Verma, Y. Yeo-Chang, and D. Zlatanova. 2015. The IPBES conceptual framework - connecting nature and people. Current Opinion in Environmental Sustainability 14:1-16. http:// dx.doi.org/10.1016/j.cosust.2014.11.002

Fisher, R. 1977. Contact and conflict: Indian-European relations in British Columbia, 1774-1890. UBC Press, Vancouver, British Columbia, Canada.

Folke, C., R. Biggs, A. V. Norström, B. Reyers, and J. Rockström. 2016. Social-ecological resilience and biosphere-based sustainability science. Ecology and Society 21(3):41. http://dx.doi.org/10.5751/ ES-08748-210341

Folke, C., L. Pritchard, F. Berkes, J. Colding, and U. Svedin. 2007. The problem of fit between ecosystems and institutions: ten years later. Ecology and Society 12(1):30. http://dx.doi.org/10.5751/ ES-02064-120130

Gauvreau, A. M., D. Lepofsky, M. Rutherford, and M. Reid. 2017. "Everything revolves around the herring": the Heiltsuk herring relationship through time. Ecology and Society 22(2):10. http://dx.doi.org/10.5751/ES-09201-220210
Gessner, S., T. Herbert, and A. Parker. 2014. Report on the status of BC First Nations languages 2014. First Peoples' Cultural Council, Brentwood Bay, British Columbia, Canada. [online] URL: http://www.fpcc.ca/files/PDF/Language/FPCCLanguageReport-141016-WEB.pdf

Gill, D. A., M. B. Mascia, G. N. Ahmadia, L. Glew, S. E. Lester, M. Barnes, I. Craigie, E. S. Darling, C. M. Free, J. Geldmann, S. Holst, O. P. Jensen, A. T. White, X. Basurto, L. Coad, R. D. Gates, G. Guannel, P. J. Mumby, H. Thomas, S. Whitmee, S. Woodley, and H. E. Fox. 2017. Capacity shortfalls hinder the performance of marine protected areas globally. Nature 543(7647):665-669. http://dx.doi.org/10.1038/nature21708

Groesbeck, A. S., K. Rowell, D. Lepofsky, and A. K. Salomon. 2014. Ancient clam gardens increased shellfish production: adaptive strategies from the past can inform food security today. Plos One 9(3). http://dx.doi.org/10.1371/journal.pone.0091235

Gutiérrez, N. L., R. Hilborn, and O. Defeo. 2011. Leadership, social capital and incentives promote successful fisheries. Nature 470(7334):386-389. http://dx.doi.org/10.1038/nature09689

Harris, C. 2002. Making native space: colonialism, resistance, and reserves in British Columbia. UBC Press, Vancouver, British Columbia, Canada.

Hartwick, E., and R. Peet. 2003. Neoliberalism and nature: the case of the WTO. ANNALS of the American Academy of Political and Social Science 590(1):188-211. http://dx.doi. org/10.1177/0002716203256721

Hebda, R. J., and R. W. Mathewes. 1984. Holocene history of cedar and native Indian cultures of the North American Pacific Coast. Science 225:711-713. http://dx.doi.org/10.1126/ science.225.4663.711

Hicks, C. C., A. Levine, A. Agrawal, X. Basurto, S. J. Breslow, C. Carothers, S. Charnley, S. Coulthard, N. Dolsak, J. Donatuto, C. Garcia-Quijano, M. B. Mascia, K. Norman, M. R. Poe, T. Satterfield, K. St. Martin, and P. S. Levin. 2016. Engage key social concepts for sustainability. Science 352(6281):38-40. http://dx. doi.org/10.1126/science.aad4977

Hoffman, K. M., K. P. Lertzman, and B. M. Starzomski. 2017. Ecological legacies of anthropogenic burning in a British Columbia coastal temperate rain forest. Journal of Biogeography 44(12):2903-2915. http://dx.doi.org/10.1111/jbi.13096

Holling, C. S., and G. K. Meffe. 1996. Command and control and the pathology of natural resource management. Conservation Biology 10(2):328-337. http://dx.doi.org/10.1046/ j.1523-1739.1996.10020328.x

Housty, W. G., A. Noson, G. W. Scoville, J. Boulanger, R. M. Jeo, C. T. Darimont, and C. E. Filardi. 2014. Grizzly bear monitoring by the Heiltsuk people as a crucible for First Nation conservation practice. Ecology and Society 19(2):70. http://dx.doi.org/10.5751/ ES-06668-190270

Howlett, M., J. Rayner, and C. Tollefson. 2009. From government to governance in forest planning? Lessons from the case of the British Columbia Great Bear Rainforest initiative. Forest Policy and Economics 11(5):383-391. http://dx.doi.org/10.1016/j. forpol.2009.01.003 
Jackley, J., L. Gardner, A. F. Djunaedi, and A. K. Salomon. 2016. Ancient clam gardens, traditional management portfolios, and the resilience of coupled human-ocean systems. Ecology and Society 21(4):20. http://dx.doi.org/10.5751/ES-08747-210420

Jones, R., C. Rigg, and E. Pinkerton. 2017. Strategies for assertion of conservation and local management rights: a Haida Gwaii herring story. Marine Policy 80:154-167. http://dx.doi. org/10.1016/j.marpol.2016.09.031

Kii'iljuus Wilson, B., and K. J. Luu Gaahlandaay Borserio. 2011. Gam tluu tllgaay aa k'iixa Gang ga; there is no land strange. Pages 187-196 in S. Steedman, Jisgang, and N. Collison, editors. That which makes us Haida-the Haida language book. Haida Gwaii Museum, Skidegate, British Columbia, Canada.

Kimmerer, R. W. 2013. Braiding sweetgrass: indigenous wisdom, scientific knowledge and the teachings of plants. Milkweed, Minneapolis, Minnesota, USA.

Klain, S. C., R. Beveridge, and N. J. Bennett. 2014. Ecologically sustainable but unjust? Negotiating equity and authority in common-pool marine resource management. Ecology and Society 19(4):52. http://dx.doi.org/10.5751/ES-07123-190452

Lagasse, C. R., W. Ou, L. D. Honka, W. I. Atlas, C. N. Hutton, J. Kotaska, and M. D. Hocking. 2014. Design considerations for community-based stream monitoring to detect changes in Pacific salmon habitats. Ecology and Society 19(4):19. http://dx.doi. org/10.5751/ES-06976-190419

Lepofsky, D., and K. Lertzman. 2008. Documenting ancient plant management in the northwest of North America. Botany 86 (2):129-145. http://dx.doi.org/10.1139/B07-094

Lepofsky, D., N. F. Smith, N. Cardinal, J. Harper, M. Morris, E. W. Gitla, R. Bouchard, D. I. D. Kennedy, A. K. Salomon, M. Puckett, and K. Rowell. 2015. Ancient shellfish mariculture on the northwest coast of North America. American Antiquity 80 (2):236-259. http://dx.doi.org/10.7183/0002-7316.80.2.236

Lertzman, K. 2009. The paradigm of management, management systems, and resource stewardship. Journal of Ethnobiology 29 (2):339-358. http://dx.doi.org/10.2993/0278-0771-29.2.339

Levin, P., and M. Poe. 2017. Conservation for the Anthropocene ocean: interdisciplinary science in support of nature and people. Academic, New York, New York, USA.

Ludwig, D., R. Hilborn, and C. Walters. 1993. Uncertainty, resource exploitation, and conservation: lessons from history. Science 260:17-36. http://dx.doi.org/10.1126/science.260.5104.17

Lutz, J. S. 2008. Makuk: a new history of Aboriginal-white relations. UBC Press, Vancouver, British Columbia, Canada.

Mackie, Q., D. Fedje, D. McLaren, N. Smith, and I. McKechnie. 2011. Early environments and archaeology of coastal British Columbia. Pages 51-103 in N. F. Bicho, J. A. Haws, and L. G. Davis, editors. Trekking the shore: changing coastlines and the antiquity of coastal settlements. Springer, New York, New York, USA. http://dx.doi.org/10.1007/978-1-4419-8219-3 3

Maffi, L. 2005. Linguistic, cultural, and biological diversity. Annual Review of Anthropology 34:599-617. http://dx.doi. org/10.1146/annurev.anthro.34.081804.120437
Matulis, B. S., and J. R. Moyer. 2017. Beyond inclusive conservation: the value of pluralism, the need for agonism, and the case for social instrumentalism. Conservation Letters 10 (3):279-287. http://dx.doi.org/10.1111/conl.12281

McGee, G., A. Cullen, and T. Gunton. 2010. A new model for sustainable development: a case study of The Great Bear Rainforest regional plan. Environment, Development and Sustainability 12(5):745-762. http://dx.doi.org/10.1007/s10668-009-9222-3

McKechnie, I., D. Lepofsky, M. L. Moss, V. L. Butler, T. J. Orchard, G. Coupland, F. Foster, M. Caldwell, and K. Lertzman. 2014. Archaeological data provide alternative hypotheses on Pacific herring (Clupea pallasii) distribution, abundance, and variability. Proceedings of the National Academy of Sciences 111 (9):E807-E816. http://dx.doi.org/10.1073/pnas.1316072111

McLaren, D., F. Rahemtulla, Gitla (E. White), and D. Fedje. 2015. Prerogatives, sea level, and the strength of persistent places: archaeological evidence for long-term occupation of the central coast of British Columbia. BC Studies (187):155. [online] URL: http://ojs.library.ubc.ca/index.php/bcstudies/article/view/186161/185693

Meadows, D. H. 2009. Thinking in systems: a primer. Earthscan, London, UK.

Menzies, C. R. 2004. Putting words into action: negotiating collaborative research in Gitxaala. Canadian Journal of Native Education 28(1/2):15. [online] URL: https://www.sfu.ca/cmns/ courses/marontate/2010/801/1-Readings/Menzies_WordsintoAction. pdf

Mistry, J., and A. Berardi. 2016. Bridging Indigenous and scientific knowledge. Science 352(6291):1274-1275. http://dx.doi. org/10.1126/science.aaf1160

Moore, M.-L., and O. Tjornbo. 2012. From coastal timber supply area to Great Bear Rainforest: exploring power in a socialecological governance innovation. Ecology and Society 17(4):26. http://dx.doi.org/10.5751/ES-05194-170426

Nabhan, G. P. 2016. Ethnobiology for the future: linking cultural and ecological diversity. University of Arizona Press, Tucson, Arizona, USA.

Ostrom, E. 2005. Understanding institutional diversity. Princeton University Press, Princeton, New Jersey, USA.

Pielke, Jr., R. A. 2007. The honest broker: making sense of science in policy and politics. Cambridge University Press, Cambridge, UK.

Pinkerton, E., and R. Davis. 2015. Neoliberalism and the politics of enclosure in North American small-scale fisheries. Marine Policy 61:303-312. http://dx.doi.org/10.1016/j.marpol.2015.03.025

Pinkerton, E., and L. John. 2008. Creating local management legitimacy. Marine Policy 32(4):680-691. http://dx.doi.org/10.1016/ j.marpol.2007.12.005

Plagányi, É. E., I. van Putten, T. Hutton, R. A. Deng, D. Dennis, S. Pascoe, T. Skewes, and R. A. Campbell. 2013. Integrating indigenous livelihood and lifestyle objectives in managing a natural resource. Proceedings of the National Academy of Sciences 110(9):3639-3644. http://dx.doi.org/10.1073/pnas.1217822110 
Poe, M. R., K. C. Norman, and P. S. Levin. 2014. Cultural dimensions of socioecological systems: key connections and guiding principles for conservation in coastal environments. Conservation Letters 7(3):166-175. http://dx.doi.org/10.1111/ $\underline{\text { conl.12068 }}$

Powell, M. 2012. Divided waters: Heiltsuk spatial management of herring fisheries and the politics of native sovereignty. Western Historical Quarterly 43:463-484. http://dx.doi.org/10.2307/ westhistquar.43.4.0463

Price, K., A. Roburn, and A. MacKinnon. 2009. Ecosystem-based management in the Great Bear Rainforest. Forest Ecology and Management 258(4):495-503. http://dx.doi.org/10.1016/j.

foreco.2008.10.010

Raworth, K. 2012. A safe and just space for humanity: can we live within the doughnut? Discussion Paper, Oxfam, Oxford, UK. [online] URL: https://www.oxfam.org/sites/www.oxfam.org/files/ dp-a-safe-and-just-space-for-humanity-130212-en.pdf

Rick, T. C., and J. M. Erlandson. 2009. Coastal exploitation. Science 325(5943):952-953. http://dx.doi.org/10.1126/science.1178539

Rick, T. C., J. M. Erlandson, T. J. Braje, J. A. Estes, M. H. Graham, and R. L. Vellanoweth. 2008. Historical ecology and human impacts on coastal ecosystems of the Santa Barbara Channel Region, California. Pages 77-101 in T. C. Rick and J. M. Erlandson, editors. Human impacts on ancient marine ecosystems: a global perspective. University of California Press, Berkeley, California, USA.

Salomon, A. K., H. Huntington, and N. K. Tanape, Sr. 2011. Imam Cimiucia: our changing sea. Sea Grant Alaska, University of Alaska Press, Fairbanks, Alaska, USA.

Salomon, A. K., N. K. Tanape, Sr., and H. P. Huntington. 2007. Serial depletion of marine invertebrates leads to the decline of a strongly interacting grazer. Ecological Applications 17 (6):1752-1770. http://dx.doi.org/10.1890/06-1369.1

Schultz, L., C. Folke, H. Österblom, and P. Olsson. 2015. Adaptive governance, ecosystem management, and natural capital. Proceedings of the National Academy of Sciences 112 (24):7369-7374. http://dx.doi.org/10.1073/pnas.1406493112

Tengö, M., E. S. Brondizio, T. Elmqvist, P. Malmer, and M. Spierenburg. 2014. Connecting diverse knowledge systems for enhanced ecosystem governance: the multiple evidence base approach. Ambio 43(5):579-591. http://dx.doi.org/10.1007/ $\underline{\text { s13280-014-0501-3 }}$

Tengö, M., R. Hill, P. Malmer, C. M. Raymond, M. Spierenburg, F. Danielsen, T. Elmqvist, and C. Folke. 2017. Weaving knowledge systems in IPBES, CBD and beyond-lessons learned for sustainability. Current Opinion in Environmental Sustainability 26-27:17-25. http://dx.doi.org/10.1016/j.cosust.2016.12.005

Trosper, R. 2009. Resilience, reciprocity and ecological economics: northwest coast sustainability. Routledge, New York, New York, USA.

Truth and Reconciliation Commission of Canada (TRC). 2015. Honouring the truth, reconciling for the future: summary of the final report of the Truth and Reconciliation Commission of Canada. Truth and Reconciliation Commission of Canada, Toronto,
Ontario, Canada. [online] URL: http://www.trc.ca/websites/ trcinstitution/File/2015/Findings/Exec_Summary_2015_05_31_web_o. pdf

Turner, N. 2014. Ancient pathways, ancestral knowledge: ethnobotany and ecological wisdom of Indigenous peoples of northwestern North America. McGill-Queen's University Press, Montreal, Quebec, Canada.

Turner, N. J. 2008. The Earth's blanket: traditional teachings for sustainable living. Douglas and McIntyre, Vancouver, British Columbia, Canada.

Turner, N. J., and F. Berkes. 2006. Coming to understanding: developing conservation through incremental learning in the Pacific Northwest. Human Ecology 34:495-513. http://dx.doi. org/10.1007/s10745-006-9042-0

Turner, N. J., F. Berkes, J. Stephenson, and J. Dick. 2013. Blundering intruders: extraneous impacts on two Indigenous food systems. Human Ecology 41(4):563-574. http://dx.doi. org/10.1007/s10745-013-9591-y

Umeek (E. R. Atleo). 2004. Tsawalk: a Nuu-chah-nulth worldview. University of British Columbia Press, Vancouver, British Columbia, Canada.

United Nations (UN). 2007. United Nations declaration on the rights of Indigenous peoples. United Nations, New York, New York, USA. [online] URL: http://www.un.org/esa/socdev/unpfii/ documents/DRIPS_en.pdf

von der Porten, S., D. Lepofsky, D. McGregor, and J. Silver. 2016. Recommendations for marine herring policy change in Canada: aligning with Indigenous legal and inherent rights. Marine Policy 74:68-76. http://dx.doi.org/10.1016/j.marpol.2016.09.007

White, E. 2011. Heiltsuk stone fish traps on the central coast of British Columbia. Pages 75-90 in M. L. Moss and A. Cannon, editors. The archaeology of North Pacific fisheries. University of Alaska Press, Fairbanks, Alaska, USA.

Wolverton, S., J. M. Nolan, and W. Ahmed. 2014. Ethnobiology, political ecology, and conservation. Journal of Ethnobiology 34 (2):125-152. http://dx.doi.org/10.2993/0278-0771-34.2.125 